as many as 10,000 new cases could be arising per week by December if the outbreak is not turned around.

Enter science. Speeding the development of treatments and vaccines is one area in which the international community is trying to move forward. On 22 October, the US Biomedical Advanced Research and Development Authority and the US Army awarded US\$17.1 million to Profectus BioSciences, a company based in Baltimore, Maryland, that is developing vaccines against Ebola based on vesicular stomatitis virus. It is the third candidate Ebola vaccine to have moved towards or into clinical trials this year. On 24 October, the WHO outlined plans to test the first two - one licensed to NewLink Genetics of Ames, Iowa, the other being developed by GlaxoSmithKline, headquartered in London. These two vaccines have already entered human safety trials and the WHO says that they could be tested in health-care workers and others in West Africa as early as December.

In the meantime, aid agencies such as Médecins Sans Frontières (also known as Doctors Without Borders) and researchers funded by the European Union will test candidate Ebola treatments, including experimental drugs, medicines already approved for other uses that could be made available 'off label', and purified plasma or blood from Ebola survivors.

Beyond treatments and vaccines, scientists have more fundamental questions, about both the Ebola virus behind the current outbreak and other viruses in the family to which it belongs, the filoviruses. This group includes Marburg virus, also capable of causing a lethal haemorrhagic fever, which killed a Ugandan health-care worker on 28 September. A third filovirus outbreak occurred this year in the Democratic Republic of the Congo, where an Ebola outbreak unrelated to that in West Africa has killed 49 people.

The emergence of three filovirus outbreaks this year and the increasing frequency and reach of such outbreaks - which have occurred every year except 2 in the past 21 years - should serve as the clearest warning possible: we urgently need to understand more about the pathology, distribution, epidemiology and clinical aspects of these viruses. A World View on page 537 argues that such science should help to steer the response; a News Feature on page 554 lays out the five most pressing questions about the filoviruses, and says why answering them might help to prevent a future outbreak or even help to bring this one under control.

For instance, new filoviruses have been discovered within the past five years, such as the Lloviu virus discovered in 2011 in bats in Spain. And scientists have learnt that these viruses have a much more widespread distribution than was suspected. The Reston virus, for example, an ebolavirus that does not seem to harm humans, has turned up in recent years in pigs in both the Philippines and China. Scientists suspect that there are more of these viruses to be found, in more places, and urgently want to understand why some are lethal to

"Whether it is Ebola virus or something completely different, there will be anext time."

It has been difficult to answer these questions for many reasons, such as the (fortunate) relative rarity and unpredictability of human filovirus outbreaks. And laboratory studies require highly contained, specialized biosafety-level-4 (BSL-4) labs - of which there are too few around the world.

Thanks to a biodefence building boom over the past decade, there are now 13 such labs planned or operating in the United States. Canada, France, Australia, Germany, the United Kingdom, South Africa, Gabon and Russia are among the select nations that also have such facilities. But there are major research-funding nations, such as Japan, that do not have BSL-4 labs, or do not allow them to perform the highest-containment research because of worries that pathogens could escape and spark lethal local epidemics.

The current Ebola outbreak proves the fallacy of that decision. The world would not be in the position it is today, with the possibility of deploying an Ebola vaccine during the current outbreak, without the existence of both high-containment facilities and money for research on diseases that are, thankfully, rare in developing countries. More of both, in more places, can only hasten our understanding of Ebola and other diseases. Because one thing is clear: whether it is Ebola virus, another filovirus or something completely different, there will be a next time.

\section{Code share}

\section{Papers in Nature journals should make computer code accessible where possible.}

A theme in Nature's ongoing campaign for the replicability and reproducibility of our research papers is that key components of publications should be available to peers who wish to validate the techniques and results.

A core element of many papers is the computer code used by authors in models, simulations and data analysis. In an ideal world, this code would always be transportable and easily used by others. In such a world, our editorial policy would be to insist on sharing to allow free use, as we already do (as far as is practicable) with data and research materials. Unfortunately, such an ideal is not easy to attain owing to the amount of extra funding and effort it would require to render some major pieces of code shareable. Nevertheless, we at Nature and the Nature research journals want to encourage as much sharing as possible.

Climate modellers have made some strides in this regard. The journal Geoscientific Model Development has a good example of such a policy (see go.nature.com/jv8g1w), and an article in Nature Geoscience discusses some of the opportunities presented by code sharing, as well as the obstacles (S. M. Easterbrook Nature Geosci. 7, 779-781; 2014).

As a leading example of transparency policies in other disciplines, the data journal GigaScience requires code used in its papers to be available, and hosts it in a way that allows others to analyse the data in publications. One point made by Easterbrook is that even if the code is shared, others might often make little or no use of it, but on some occasions the take-up will be large.

Nature and the Nature journals have decided that, given the diversity of practices in the disciplines we cover, we cannot insist on sharing computer code in all cases. But we can go further than we have in the past, by at least indicating when code is available. Accordingly, our policy now mandates that when code is central to reaching a paper's conclusions, we require a statement describing whether that code is available and setting out any restrictions on accessibility. Editors will insist on availability where they consider it appropriate: any practical issues preventing code sharing will be evaluated by the editors, who reserve the right to decline a paper if important code is unavailable. Moreover, we will provide a dedicated section in articles in which any information on computer code can be placed. And we will work with individual communities to put together best-practice guidelines and possibly more-detailed rules.

For full details, see our guide for authors at $\rightarrow$ NATURE.COM To comment online, click on Editorials at: go.nature.com/xhunqv go.nature.com/o5ykhe. For an archive of our content and initiatives concerning reproducibility, see http://www.nature.com/nature/focus/ reproducibility. 